\title{
Impact of Patient and Lesion Complexity on Long-Term Outcomes Following Coronary Revascularization with New-Generation Drug-Eluting Stents
}

\author{
Konstantinos C. Koskinas, MDa; Masanori Taniwaki, MDª Fabio Rigamonti, MD; \\ Dik Heg, $\mathrm{PhD}^{\mathrm{c}}$; Marco Roffi, $\mathrm{MD}^{\mathrm{b}}$; David Tüller, $\mathrm{MD}^{\mathrm{d}}$; Olivier Muller, MD; \\ Andre Vuillomenet, $\mathrm{MD}^{\mathrm{f}}$, Stephane Cook, $\mathrm{MD}^{\mathrm{g}}$; Daniel Weilenmann, $\mathrm{MD}^{\mathrm{h}}$; \\ Christopher Kaiser, MD'; Peiman Jamshidi, MD'; Peter Jüni, MD; \\ Stephan Windecker, $\mathrm{MD}^{\mathrm{a}}$; Thomas Pilgrim, $\mathrm{MD}^{\mathrm{a}}$
}

\footnotetext{
${ }^{a}$ Department of Cardiology, Swiss Cardiovascular Center, University Hospital, Bern, Switzerland ${ }^{\mathrm{b}}$ Department of Cardiology, University Hospital, Geneva, Switzerland

${ }^{\mathrm{c}}$ Institute of Social and Preventive Medicine and Clinical Trials Unit, Bern University Hospital, Switzerland

${ }^{\mathrm{d}}$ Department of Cardiology, Triemlispital, Zurich, Switzerland

${ }^{\mathrm{e}}$ Department of Cardiology, University Hospital, Lausanne, Switzerland

${ }^{\mathrm{f}}$ Department of Cardiology, Kantonsspital, Aarau, Switzerland

${ }^{\text {g }}$ Department of Cardiology, University Hospital, Fribourg, Switzerland

${ }^{\mathrm{h}}$ Department of Cardiology, Kantonsspital, St. Gallen, Switzerland

${ }^{\mathrm{i}}$ Department of Cardiology, University Hospital, Basel, Switzerland

${ }^{j}$ Department of Cardiology, Kantonsspital, Luzern, Switzerland

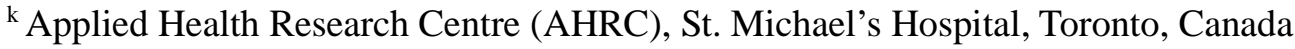

Running head: New-generation DES in complex patients

\author{
Corresponding author \\ Stephan Windecker, MD \\ Professor and Head of Cardiology \\ Department of Cardiology \\ Bern University Hospital \\ 3010 Bern, Switzerland \\ Tel: +41316324497 \\ E-mail: stephan.windecker@insel.ch
}




\begin{abstract}
Long-term clinical outcomes of new-generation drug-eluting stents in complex anatomic and clinical settings are not well defined. This study assessed the impact of patient and lesion complexity on 2-year outcomes following coronary revascularization with ultrathin strut biodegradable-polymer (BP) sirolimus-eluting stents (SES) vs. durable-polymer (DP) everolimus-eluting stents (EES). In a pre-specified analysis of the BIOSCIENCE randomized trial (NCT01443104), complex patients (911 of 2,119; 43\%) were defined by the presence of acute ST-elevation myocardial infarction; left ventricular ejection fraction $\leq 30 \%$; renal dysfunction; insulin-treated diabetes; treatment of ostial lesion, bypass graft, unprotected left main lesion; or 3-vessel intervention. The primary endpoint was target-lesion failure (TLF), a composite of cardiac death, target-vessel myocardial infarction (MI), and clinically-indicated target lesion revascularization. At 2 years, complex compared with simple patients had a higher risk of TLF (14.5\% vs. 7.4\%, RR 2.05, 95\% CI 1.56-2.69; $\mathrm{p}<0.001)$. The difference was sustained beyond 1 year on landmark analysis. Complex patients had higher rates of the patient-oriented composite endpoint (POCE) of death, any MI, or any revascularization (23\% vs. $14.4 \%$; $\mathrm{p}<0.001$ ) as well as definite stent thrombosis (1.6\% vs. 0.4\%, p=0.006). There were no differences in TLF and POCE between the BP-SES vs. DP-EES, consistently among simple and complex patients. In conclusion, patient and lesion complexity had a durable adverse impact on clinical outcomes throughout 2 years of follow-up in this all-comers randomized trial. Safety and efficacy of new-generation BP-SES and DP-EES were comparable, irrespective of complexity status.
\end{abstract}

Keywords: biodegradable polymer; drug-eluting stent; complex intervention. 
New-generation drug-eluting stents (DES) are frequently implanted in complex anatomic and clinical settings ${ }^{1,2}$ and are recommended for unrestricted use across patient and lesion subsets. ${ }^{3,4}$ Studies analyzing bare-metal stents (BMS) and early-generation DES showed less favorable outcomes in patients treated for complex (“off-label”) indications. ${ }^{4-6}$ In contrast, few data exist regarding new-generation DES in complex patients and lesions, and are limited by short- to mid-term follow-up durations.,8 Biodegradable polymer DES (BP-DES) were conceived to overcome safety issues of early-generation durable polymer (DP) DES, as polymer remnants within the arterial wall may be implicated in late stent thrombosis or delayed restenosis. The BIOSCIENCE randomized trial reported non-inferiority of the ultra-thin strut BP sirolimus-eluting stent (BP-SES) compared with DP everolimus-eluting stent (DP-EES). ${ }^{9}$ Other studies showed clinical ${ }^{10,11}$ and angiographic non-inferiority ${ }^{12}$ of thin-strut BP platforms. Whether these performance profiles are maintained in patients undergoing complex interventions remains unknown. This study sought to determine the impact of patient and lesion complexity on 2-year clinical outcomes following revascularization with new-generation DES, and to compare the safety and efficacy of ultrathin-strut BP-SES vs. DP-EES in relation to complexity status in a large-scale randomized trial with minimal exclusion criteria.

\section{Methods}

This is a pre-specified analysis of the BIOSCIENCE trial (NCT01443104), ${ }^{9,13}$ a prospective, multicenter trial that compared an ultrathin strut stent covered with a BP releasing sirolimus (Orsiro; Biotronik AG, Bülach, Switzerland) with a thin strut DP-EES (XIENCE PRIME/Xpedition®; Abbott Vascular, Santa Clara, CA, USA).$^{13}$ Briefly, patients with stable coronary artery disease (CAD) or acute coronary syndrome (ACS) and at least 1 lesion with diameter stenosis $>50 \%$ (de novo or restenosis) in a native vessel or bypass graft with reference vessel diameter between 2.25 and $4.0 \mathrm{~mm}$ were eligible for inclusion. There were no restrictions to the number of treated lesions or vessels. The study was approved by institutional ethics committees of all participating sites. All patients provided written informed consent. 
Procedures were performed according to current standards. ${ }^{3}$ Procedural anticoagulation included unfractionated heparin 5,000 IU or 70-100 IU/kg. The use of glycoprotein IIb/IIIa inhibitors and bivalirudin was left at the operator's discretion. Antiplatelet treatment was initiated before or at the time of PCI, and consisted of acetylsalicylic acid (ASA) in combination with a loading dose of clopidogrel 600mg, prasugrel 60mg, or ticagrelor 180mg. Dual antiplatelet therapy was recommended for 12 months and consisted of ASA $100 \mathrm{mg}$ and a $\mathrm{P}_{2} \mathrm{Y}_{12}$ inhibitor, followed by ASA monotherapy indefinitely.

We applied an extended definition of complexity including clinical, lesion-related, and procedural characteristics previously shown to predict adverse outcomes following PCI with new-generation DES. ${ }^{14}$ Complex patients were defined by the presence of at least 1 of the following: acute STEMI (within 24hours); left ventricular ejection fraction $\leq 30 \%$; renal dysfunction (GFR $<60 \mathrm{ml} / \mathrm{min}$ ); insulin-treated diabetes; and treatment of ostial lesion, bypass graft, unprotected left main lesion, or $>2$ vessels.

An independent clinical events committee adjudicated all events. Myocardial infarction (MI) was defined according to an extended historical definition. ${ }^{15}$ Clinical follow-up was performed at 30 days, 12 and 24 months. The pre-specified primary endpoint ${ }^{9,13}$ was target lesion failure (TLF), a composite of cardiac death, target-vessel MI, and clinically indicated target-lesion revascularization (TLR) at 2 years. Secondary endpoints included a patient-oriented composite endpoint (POCE) of all-cause death, any MI, or any revascularization; and individual components of composite endpoints. The principle safety endpoint was stent thrombosis, defined according to the Academic Research Consortium. ${ }^{16}$

Continuous variables are summarized as mean \pm standard deviation, and categorical ones as actual numbers and percentages. Baseline and procedural characteristics were compared using unpaired t-tests, chi square tests, or Fisher's exact tests. P-values for lesion-level characteristics were based on general or generalized linear mixed models to account for the non-independence of lesions in the same patient. We used time to first event for each outcome and report Kaplan-Meier estimates of event rates. We used the Mantel-Cox method to calculate risk ratios (RR) with 95\% confidence intervals (CI) from the log-rank test. Landmark Mantel-Cox’s models compared outcomes between complex and simple patients at 1 year, and the p-value for the interaction was based on the approximate chi square test for unequal rate ratios 
(effect modification). For each event, patients were censored at the time of first event. Simple and complex patients treated with BP-SES were compared with those treated with DP-EES, and interaction p values were calculated. Analyses were performed according to the intention-to-treat principle with Stata version 14 . A 2-sided p-value $<0.05$ was considered statistically significant.

\section{Results}

Out of 2,119 patients enrolled, 911 complex patients (43\%) were allocated to BP-SES (n=487) or DP-EES ( $\mathrm{n}=424)$. Simple patients $(1,208 ; 57 \%)$ were randomized to BP-SES $(\mathrm{n}=576)$ or DP-EES $(\mathrm{n}=632)$ (Supplementary Figure 1). The most frequent complexity characteristics were acute STEMI (34.9\%), renal dysfunction (32.7\%), and insulin-treated diabetes (17.6\%) (Figure 1). Compared with simple patients, complex patients were older, more commonly female, with more frequent history of previous revascularization (Table 1). Variables were well-balanced between the BP-SES and DP-EES arms for both complex and simple patients (Supplementary Table 1). Complex patients had a higher number of lesions treated, and received more stents per lesion with greater length and diameter (Table 2).

The primary endpoint, TLF at 2 years, occurred in 128 complex patients (14.5\%) vs. 86 simple patients (7.4\%) (RR 2.05, 95\% CI 1.56-2.69; p=0.001). Consistent differences were observed in all components of the primary endpoint (Table 3). Complex compared with simple patients had higher risk of the POCE (RR 1.67, 95\% CI 1.36-2.05; p<0.001) and all-cause mortality (RR 2.81, 95\% CI 1.87-4.24; $\mathrm{p}<0.001$ ). Kaplan-Meier curves for TLF and POCE are shown in Figure 2. The risk of TLF and POCE was highest in patients with more than 1 complexity characteristics (Supplementary Figure 2). Definite stent thrombosis within 2 years was more frequent among complex patients ( $1.6 \%$ vs. $0.4 \%, \mathrm{p}=0.006)$.

Landmark analyses for TLF and POCE set at 30 days and 1 year are illustrated in Supplementary Figure 3 and Figure 3, respectively. Complex compared with simple patients had higher risk of TLF consistently up to 1 year (RR 1.77, 95\% CI 1.27-2.46) and for the timeframe between 1 and 2 years (RR 2.78, 95\% CI 1.70-4.54) (pinteraction = 0.13). Similarly, the risk of POCE was higher in complex patients consistently during the first as well as the second year of follow-up (Figure 3 and Supplementary Table 
2). Complex vs. simple patients had higher one-year rates of definite stent thrombosis $(1.2 \%$ vs. $0.2 \%$, $\mathrm{p}=0.002)$ but had similar rates of very late stent thrombosis ( $0.4 \%$ vs. $0.3 \%$; $=0.69)$.

Among complex patients, BP-SES and DP-EES were associated with similar risk of TLF (RR 0.76, 95\% CI 0.54-1.08; p=0.12), POCE (RR 0.99, 95\% CI 0.76-1.31; p=0.97) (Figure 4), and definite stent thrombosis (RR 1.57, 95\% CI 0.52-4.68; p=0.42) (Table 4). Similarly, no significant difference was observed between BP-SES and DP-EES with regard to TLF (RR 1.35, 95\% CI 0.88-2.06; p=0.17), POCE (RR 1.22, 95\% CI 0.90-1.66; p=0.19) and stent thrombosis throughout 2 years (RR 0.75, 95\% CI 0.12-4.52; $\mathrm{p}=0.75$ ) among simple patients (Table 4). The DP-EES was associated with lower cardiac mortality among simple patients, but with higher cardiac mortality among complex patients (Table 4).

\section{Discussion}

The findings of the present study can be summarized as follows. First, patient and lesion complexity was associated with higher long-term risk of stent-related and patient-related adverse events following PCI with new-generation DES. Second, complexity had a durable adverse impact extending beyond the first year of follow-up. Third, primary safety and efficacy endpoints were comparable between the ultra-thin strut BP-SES and DP-EES, consistently among complex and simple patients. These findings add to previous investigations that assessed complex interventions using earlier-generation devices. ${ }^{5,6}$ They also build upon studies that demonstrated comparable efficacy and safety profiles of thin-strut BP-DES vs. DP-EES but did not address the possibly interrelating effect of patient and lesion complexity. ${ }^{9-12}$

While on-label FDA indication for coronary DES is limited to low-risk, stable CAD patients with single simple lesions, PCI is frequently performed in more complex settings. Observational studies with primarily early-generation DES showed marked attenuation of the benefits of DES with off-label vs. on-label use. ${ }^{4,5}$ New-generation DES have improved the safety and efficacy of PCI ${ }^{3,4}$; however, there are limited data regarding long-term performance of new-generation DES in complex settings. ${ }^{7}$ The present analysis from a broadly inclusive contemporary trial uniquely addressed the impact of patient and lesion complexity on long-term clinical outcomes with the unrestricted use of 2 new-generation DES. 
Interventions in complex patients were associated with less-favorable outcomes including 2-fold higher risk of TLF, 3-fold higher mortality, and increased risk of all ischemic endpoints, particularly among patients with multiple concomitant complexity features. These differences emerged following the early phase (30 days), they extended beyond the first year and were at least as pronounced during the second year of follow-up. These observations may have implications for long-term risk stratification and patient management, as complex patients are likely to benefit more from aggressive, sustained secondary prevention therapies. ${ }^{17}$

Defining characteristics of complexity in this study included comorbidities with a well-established role in the pathobiology of atherosclerotic disease and in-stent restenosis (insulin-treated diabetes, renal dysfunction); clinical conditions portending sustained atherothrombotic risk (acute STEMI); and challenging anatomic settings known to adversely affect procedural and longer-term PCI outcomes. These complexity features have been closely linked to adverse PCI outcomes in previous relevant reports focusing on earlier devices. ${ }^{5,8}$

The rates of definite stent thrombosis within 2 years (0.9\%) is comparable with other studies with new-generation DES, ${ }^{18}$ but was 4 -fold increased among complex vs. simple patients. Whether complex patients might benefit from more prolonged dual antiplatelet therapy or potent $\mathrm{P}_{2} \mathrm{Y}_{12}$ inhibitors even in non-ACS settings merits investigation in dedicated studies, also accounting for individual bleeding risk. These findings require cautious interpretation owing to the small numbers of events, and the possibly heterogeneous ischemic risk among patients encompassed in our complexity definition.

Decision-making regarding the preferred modality of coronary revascularization (PCI vs. CABG) is a challenging process accounting for patient-related factors, anatomic configurations, and procedural feasibility. ${ }^{3}$ The present findings should be interpreted in view of the following considerations. First, PCI is the cornerstone for management of acute STEMI (the most common complexity feature in this study), whereas CABG has very limited role in this context. ${ }^{3}$ Second, improvements in stent technologies appear to have narrowed the outcome gap between CABG and PCI in patients with advanced, complex disease. ${ }^{19}$ Third, several of the complexity characteristics are also known to adversely affect prognosis following 
bypass surgery, including insulin-treated diabetes, ${ }^{20}$ depressed left ventricular function, ${ }^{21}$ and renal dysfunction. ${ }^{22}$ Therefore, rather than challenging the value of new-generation DES in complex scenarios, the present observations point to the importance of preventing long-term PCI complications particularly among complex patients. Potential means may include meticulous attention to the acute PCI result, possibly intracoronary imaging-guided interventions in selected anatomic subsets, ${ }^{3,23}$ and optimization of post-PCI antithrombotic treatment and secondary prevention therapies. ${ }^{9}$

New-generation DES have improved late and very-late safety compared with early-generation DES. The combination of an ultrathin stent platform with a BP represents the next generation of coronary stent technology. While thin-strut BP-DES have demonstrated equivalent clinical and angiographic outcomes compared with the DP-EES, ${ }^{9-12}$ this is the first report assessing the relative safety and efficacy of a new-generation BP-DES specifically in complex patient and lesion subsets. We found that the BP-SES matched the clinical performance of DP-EES, the contemporary benchmark for PCI. Pre-specified primary endpoints (TLF, POCE) did not differ in relation to stent type, irrespective of complexity status. The hypothesis-generating observation of lower cardiac mortality of BP-SES vs. DP-SES treated patients in the complex, but not in the simple patient group requires further investigation. Great caution is required in interpreting these results in view of the modestly sized subgroups after stratification for both complexity status and stent type.

This study has limitations. First, our findings are presented as hypothesis-generating only, being a post hoc analysis of a trial not designed to assess outcomes in relation to complexity. Second, the study was powered for the primary endpoint but is underpowered to detect differences in individual components or rare events, such as stent thrombosis. Third, this analysis was not designed to address the causal vs. associative interrelation of complexity factors with adverse outcomes. Fourth, although the definition of complexity was not pre-defined, the present complexity analysis was pre-specified in the study protocol. ${ }^{13}$ Finally, the biodegradable polymer of the BP-SES degrades over a period of 12 to 24 months; hence, potential differences in outcomes may only emerge during very long-term (more than 2-year) follow-up. 
Published in final edited form as: Am J Cardiol. 2017 Feb 15;119(4):501-507. doi: 10.1016/j.amjcard.2016.10.038

- 9 - 
1. Serruys PW, Silber S, Garg S, van Geuns RJ, Richardt G, Buszman PE, Kelbaek H, van Boven AJ, Hofma SH, Linke A, Klauss V, Wijns W, Macaya C, Garot P, DiMario C, Manoharan G, Kornowski R, Ischinger T, Bartorelli A, Ronden J, Bressers M, Gobbens P, Negoita M, van Leeuwen F, Windecker S. Comparison of zotarolimus-eluting and everolimus-eluting coronary stents. N Engl J Med 2010; 363: 136-146.

2. Rao SV, Shaw RE, Brindis RG, Klein LW, Weintraub WS, Peterson ED. On- versus of label use of drug-eluting coronary stents in clinical practice (report from the American College of Cardiology National Cardiovascular Data Registry [NCDR]). Am J Cardiol 2006;97:1478-1481.

3. Windecker S, Kolh P, Alfonso F, Collet JP, Cremer J, Falk V, Filippatos G, HammC, Head SJ, Juni P, Kappetein AP, Kastrati A, Knuuti J, Landmesser U, Laufer G,Neumann FJ, Richter DJ, Schauerte P, Sousa Uva M, Stefanini GG, Taggart DP,Torracca L, Valgimigli M, Wijns W, Witkowski A. 2014 ESC/EACTS guidelines on myocardial revascularization: the Task Force on Myocardial Revascularization of the European Society of Cardiology (ESC) and the European Association for Cardio-Thoracic Surgery (EACTS). Eur Heart J 2014;35:2541-2619.

4. Byrne RA, Serruys PW, Baumbach A, Escaned J, Fajadet J, James S, Joner M, Oktay S, Jüni P, Kastrati A, Sianos G, Stefanini GG, Wijns W, Windecker S. Report of a European Society of Cardiology-European Association of Percutaneous Cardiovascular Interventions task force on the evaluation of coronary stents in Europe: executive summary. Eur Heart J 2015;36(38):2608-2620.

5. Marroquin OC, Selzer F, Mulukutla SR, Williams DO, Vlachos HA, Wilensky RL, Tanguay JF, Holper EM, Abbott JD, Lee JS, Smith C, Anderson WD, Kelsey SF, Kip KE. A comparison of bare-metal and drug-eluting stents for off-label indications N Engl J Med 2008;358:342-352.

6. Wilensky RL, Selzer F, Johnston J, Laskey WK, Klugherz BD, Block P, Cohen H, Detre K, Williams DO. Relation of percutaneous coronary intervention of complex lesions to clinical outcomes (from the NHLBI Dynamic Registry). Am J Cardiol 2002;90:216-221.

7. Stefanini GG, Serruys PW, Silber S, Khattab AA, van Geuns RJ, Richardt G, Buszman PE, Kelbæk H, van Boven AJ, Hofma SH, Linke A, Klauss V, Wijns W, Macaya C, Garot P, Di Mario C, Manoharan G, Kornowski R, Ischinger T, Bartorelli AL, Gobbens P, Windecker S. The impact of patient and lesion complexity on clinical and angiographic outcomes after revascularization with zotarolimus- and everolimus-eluting stents: a substudy of the RESOLUTE All Comers Trial. J Am Coll Cardiol 2011;57:2221-2232.

8. Goto K, Lansky AJ, Ng VG, Pietras C, Nargileci E, Mehran R, Parise H, Feit F, Ohman EM, White HD, Bertrand ME, Desmet W, Hamon M, Stone GW. Prognostic value of angiographic lesion complexity in patients with acute coronary syndromes undergoing percutaneous coronary intervention (from the acute catheterization and urgent intervention triage strategy trial). Am J Cardiol 2014;114:1638-1645. 
9. Pilgrim T, Heg D, Roffi M, Tuller D, Muller O, Vuilliomenet A, Cook S, Weilenmann D, Kaiser C, Jamshidi P, Fahrni T, Moschovitis A, Noble S, EberliFR, Wenaweser P, Juni P, Windecker S. Ultrathin strut biodegradable polymersirolimus-eluting stent versus durable polymer everolimus-eluting stent for percutaneous coronary revascularisation (BIOSCIENCE): a randomised, singleblind, non-inferiority trial. Lancet 2014;384:2111-2122.

10. Saito S, Valdes-Chavarri M, Richardt G, Moreno R, Iniguez Romo A, Barbato E, Carrie D, Ando K, Merkely B, Kornowski R, Eltchaninoff H, James S, Wijns W; Investigators CI. A randomized, prospective, intercontinental evaluation of a bioresorbable polymer sirolimus-eluting coronary stent system: the CENTURY II (Clinical Evaluation of New Terumo Drug-Eluting Coronary Stent System in the Treatment of Patients with Coronary Artery Disease) trial. Eur Heart J 2014;35:2021-2031.

11. Kereiakes DJ, Meredith IT, Windecker S, Lee Jobe R, Mehta SR, Sarembock IJ, Feldman RL, Stein B, Dubois C, Grady T, Saito S, Kimura T, Christen T, Allocco DJ, Dawkins KD. Efficacy and safety of a novel bioabsorbable polymer-coated, everolimus-eluting coronary stent: the EVOLVE II Randomized Trial. Circ Cardiovasc Interv 2015;8:e002372.

12. Windecker S, Haude M, Neumann FJ, Stangl K, Witzenbichler B, Slagboom T, Sabate M, Goicolea J, Barragan P, Cook S, Piot C, Richardt G, Merkely B, Schneider H, Bilger J, Erne P, Waksman R, Zaugg S, Juni P, Lefevre T. Comparison of a novel biodegradable polymer sirolimus-eluting stent with a durable polymer everolimus-eluting stent: results of the randomized BIOFLOW II trial. Circ Cardiovasc Interv 2015;8:e001441.

13. Pilgrim T, Roffi M, Tüller D, Muller O, Vuilliomenet A, Cook S, Weilenmann D, Kaiser C, Jamshidi P, Heg D, Jüni P, Windecker S. Randomized comparison of biodegradable polymer sirolimus-eluting stents versus durable polymer everolimus-eluting stents for percutaneous coronary revascularization: rationale and design of the BIOSCIENCE trial. Am Heart J 2014;168:256-261.

14. Taniwaki M, Stefanini GG, Silber S, Richardt G, Vranckx P, Serruys PW, Buszman PE, Kelbaek H, Windecker S; RESOLUTE All-Comers Investigators. 4-year clinical outcomes and predictors of repeat revascularization in patients treated with new-generation drug-eluting stents: a report from the RESOLUTE All-Comers trial. J Am Coll Cardiol 2014;63:1617-1625.

15. Vranckx P, Cutlip DE, Mehran R, Kint PP, Silber S, Windecker S, Serruys PW. Myocardial infarction adjudication in contemporary all-comer stent trials: balancing sensitivity and specificity. Addendum to the historical MI definitions used in stent studies. EuroIntervention 2010;5:871-874.

16. Cutlip DE, Windecker S, Mehran R, Boam A, Cohen DJ, van Es GA, Steg PG, Morel MA, Mauri L, Vranckx P, McFadden E, Lansky A, Hamon M, Krucoff MW, Serruys PW; Academic Research C. Clinical end points in coronary stent trials: a case for standardized definitions. Circulation 2007;115:2344-2351. 
17. Iqbal J, Zhang YJ, Holmes DR, Morice MC, Mack MJ, Kappetein AP, Feldman T, Stahle E, Escaned J, Banning AP, Gunn JP, Colombo A, Steyerberg EW, Mohr FW, Serruys PW. Optimal medical therapy improves clinical outcomes in patients undergoing revascularization with percutaneous coronary intervention or coronary artery bypass grafting: insights from the Synergy Between Percutaneous Coronary Intervention with TAXUS and Cardiac Surgery (SYNTAX) trial at the 5-yearfollow-up. Circulation 2015;131:1269-1277.

18. Silber S, Windecker S, Vranckx P, Serruys PW; RESOLUTE All Comers investigators. Unrestricted randomised use of two new generation drug-eluting coronary stents: 2-year patient-related versus stent-related outcomes from the RESOLUTE All Comers trial. Lancet 2011;377:1241-1247.

19. Bangalore S, Toklu B, Feit F. Outcomes with coronary artery bypass graft surgery versus percutaneous coronary intervention for patients with diabetes mellitus: can newer generation drug-eluting stents bridge the gap? Circ Cardiovasc Interv 2014;7:518-525.

20. Dangas GD, Farkouh ME, Sleeper LA, Yang M, Schoos MM, Macaya C, Abizaid A, Buller CE, Devlin G, Rodriguez AE, Lansky AJ, Siami FS, Domanski M, Fuster V; FREEDOM Investigators. Long-term outcome of PCI versus CABG in insulin and non-insulin-treated diabetic patients: results from the FREEDOM trial. J Am Coll Cardiol 2014;64:1189-1197.

21. Topkara VK, Cheema FH, Kesavaramanujam S, Mercando ML, Cheema AF, Namerow PB, Argenziano M, Naka Y, Oz MC, Esrig BC. Coronary artery bypass grafting in patients with low ejection fraction. Circulation 2005;112:I344-350.

22. Cooper WA, O'Brien SM, Thourani VH, Guyton RA, Bridges CR, Szczech LA, Petersen R, Peterson ED. Impact of renal dysfunction on outcomes of coronary artery bypass surgery: results from the Society of Thoracic Surgeons National Adult Cardiac Database. Circulation 2006;113:1063-1070.

23. Koskinas KC, Ughi GJ, Windecker S, Tearney GJ, Räber L. Intracoronary imaging of coronary atherosclerosis: validation for diagnosis, prognosis and treatment. Eur Heart J 2016;37:524-535. 
Published in final edited form as: Am J Cardiol. 2017 Feb 15;119(4):501-507.

doi: 10.1016/j.amjcard.2016.10.038

$-13-$

\section{Figures}

Figure 1. Frequency of complexity characteristics (A) and number of complexity features per patient (B) among complex patients ( $\mathrm{n}=911)$.
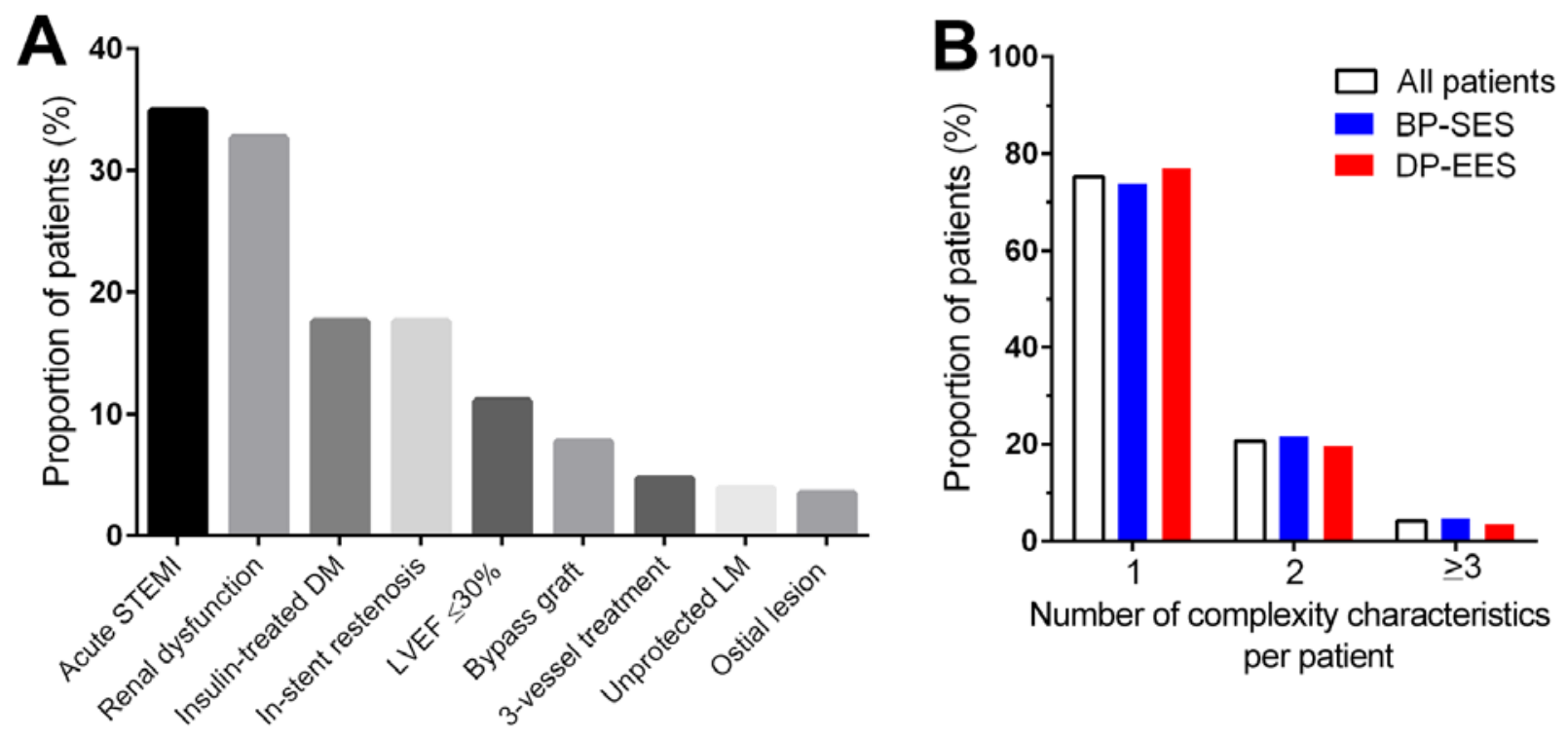
Figure 2. Kaplan-Meier curves for the primary endpoint $(A)$ and the patient-oriented composite endpoint (POCE) (B) within 2-year follow-up in complex and simple patients.

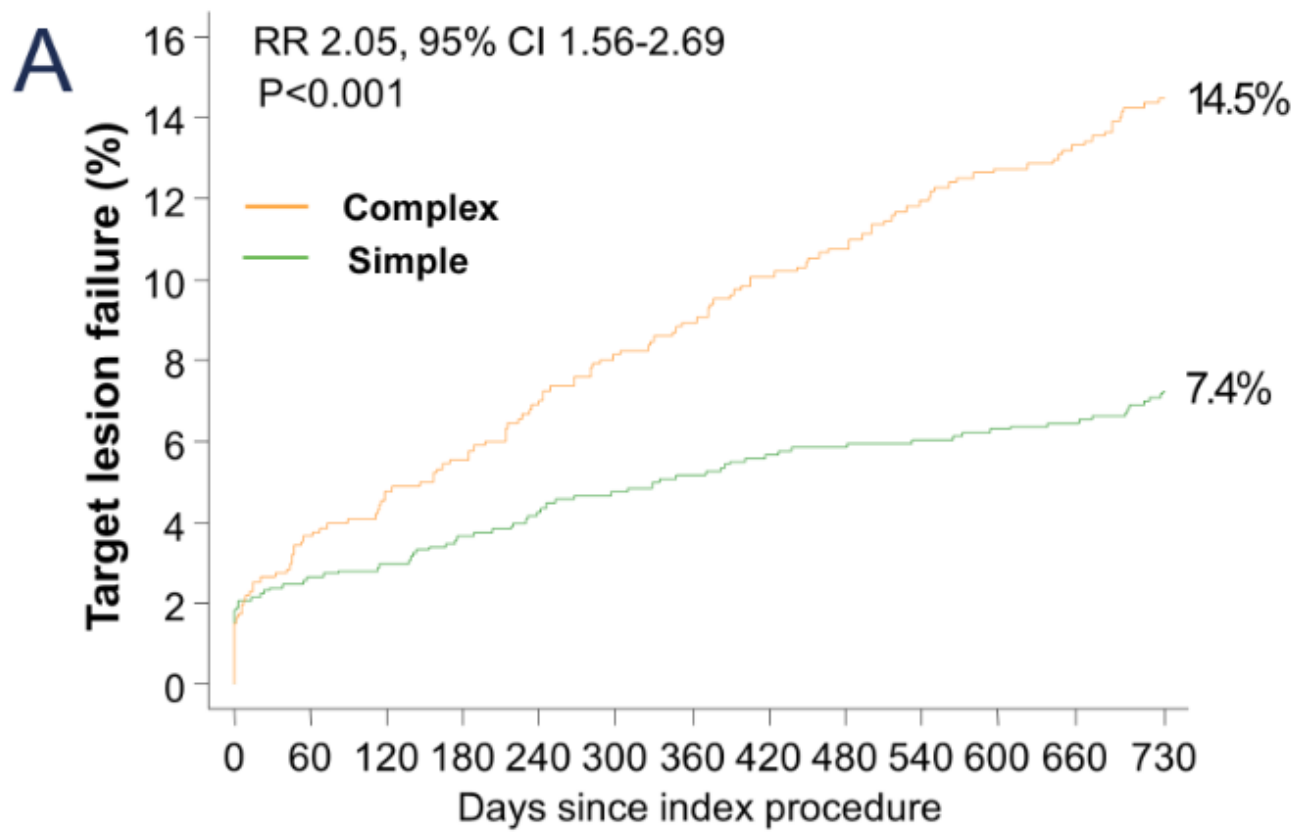

Number at risk

Simple 1208115911541145113711301121109310881083108010781063

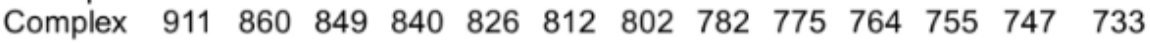

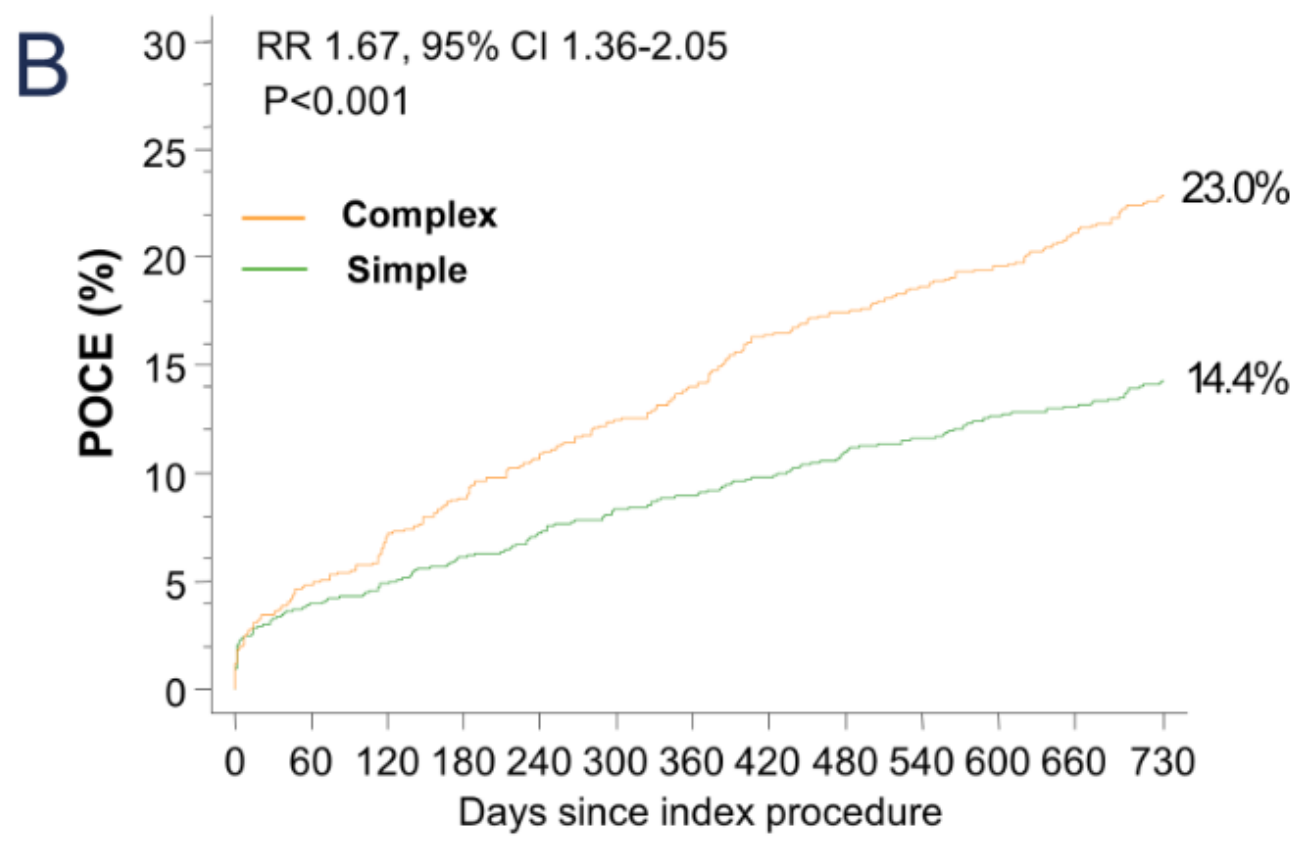

Number at risk

Simple 120811451134112011061093108210541039103210201015997 $\begin{array}{llllllllllllll}\text { Complex } & 911 & 851 & 831 & 815 & 798 & 783 & 769 & 739 & 730 & 719 & 711 & 697 & 680\end{array}$ 


\section{$-15-$}

Figure 3. Kaplan-Meier curves for the primary endpoint (A) and the patient-oriented composite endpoint (POCE) $(B)$ in relation to complexity status with landmark set at one year.
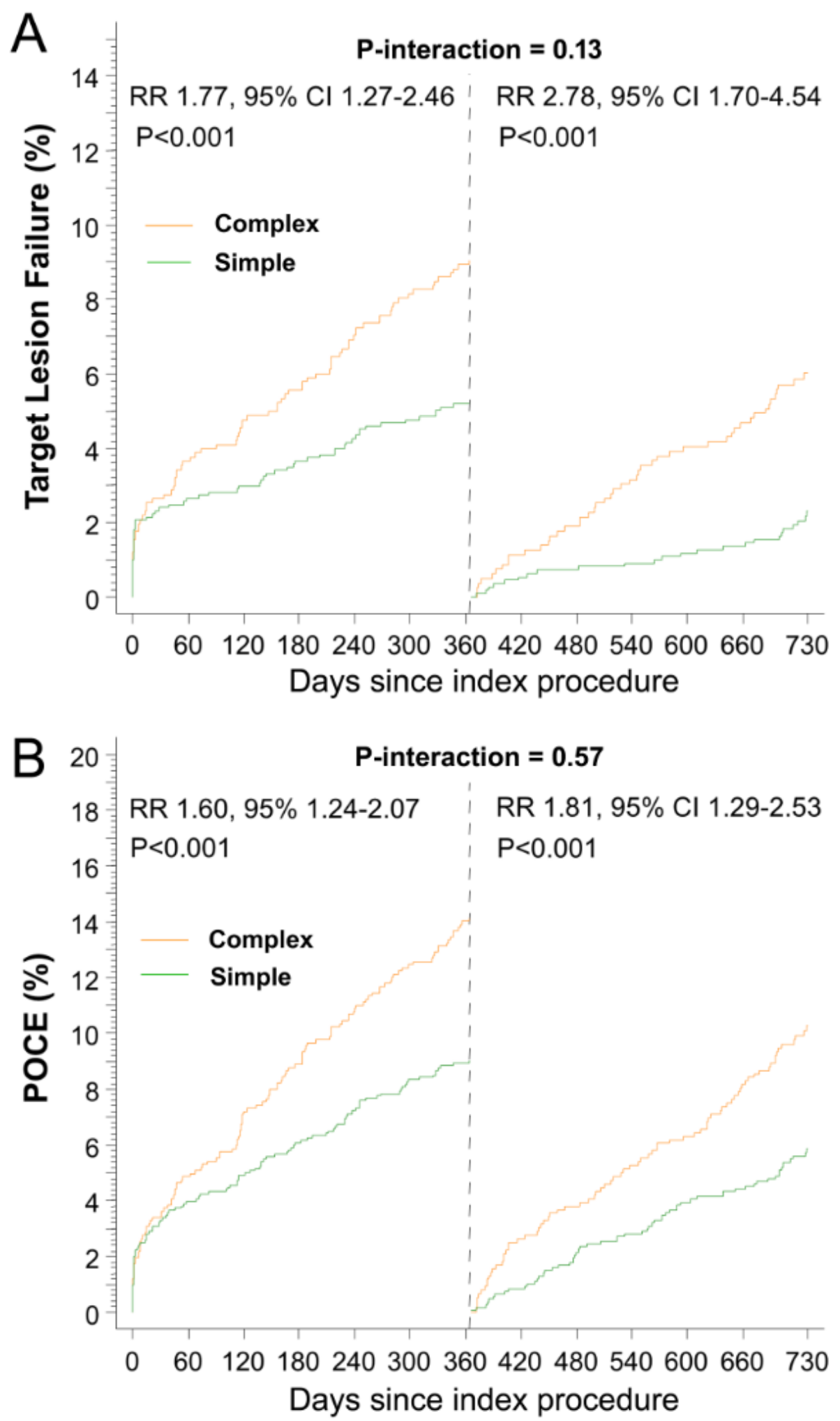
Published in final edited form as: Am J Cardiol. 2017 Feb 15;119(4):501-507.

doi: 10.1016/j.amjcard.2016.10.038

\section{$-16-$}

Figure 4. Kaplan-Meier curves for the primary endpoint $(A, B)$ and the patient-oriented composite endpoint (POCE) $(C, D)$ in relation to stent type among complex patients (left) and simple patients (right).

\section{Complex patients}

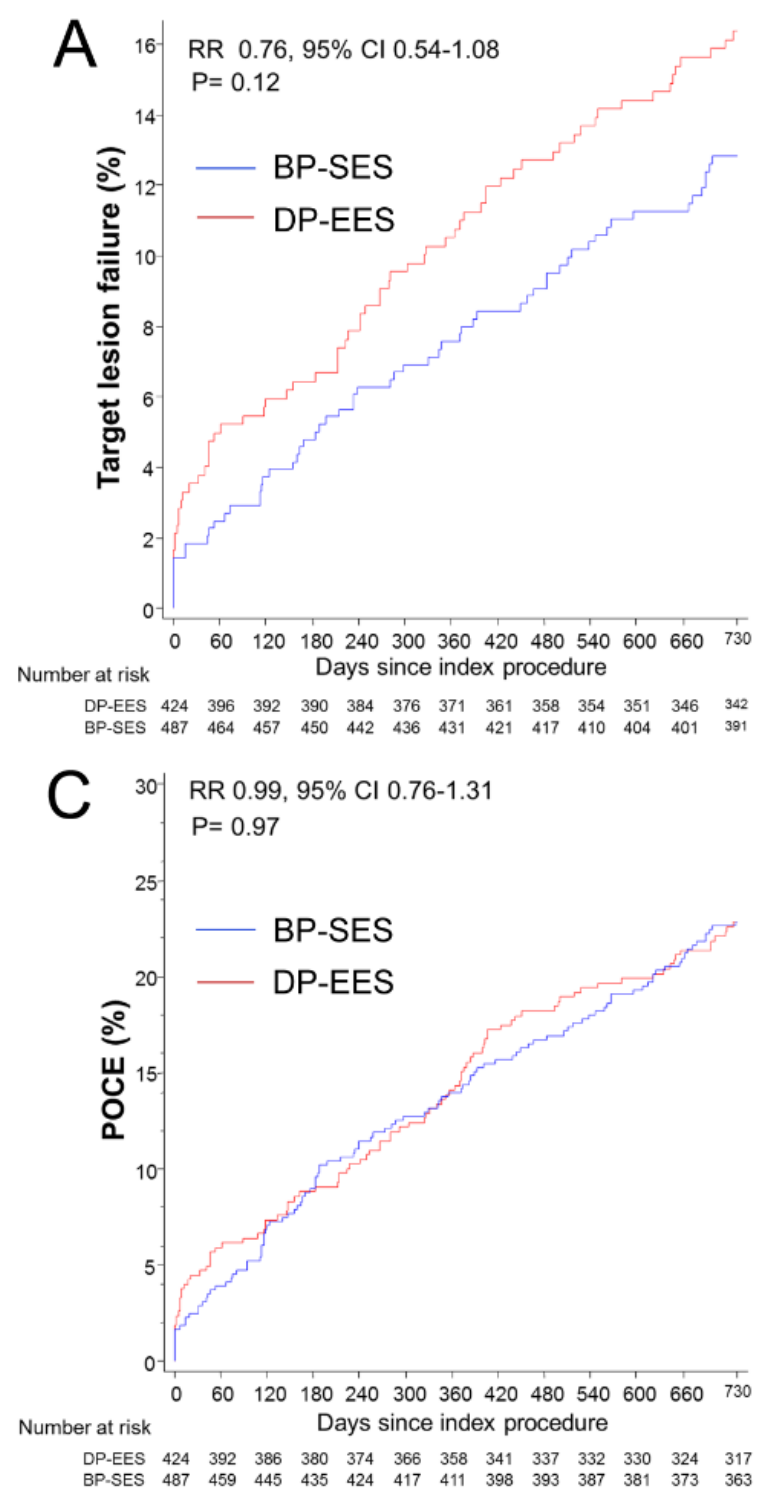

\section{Simple patients}

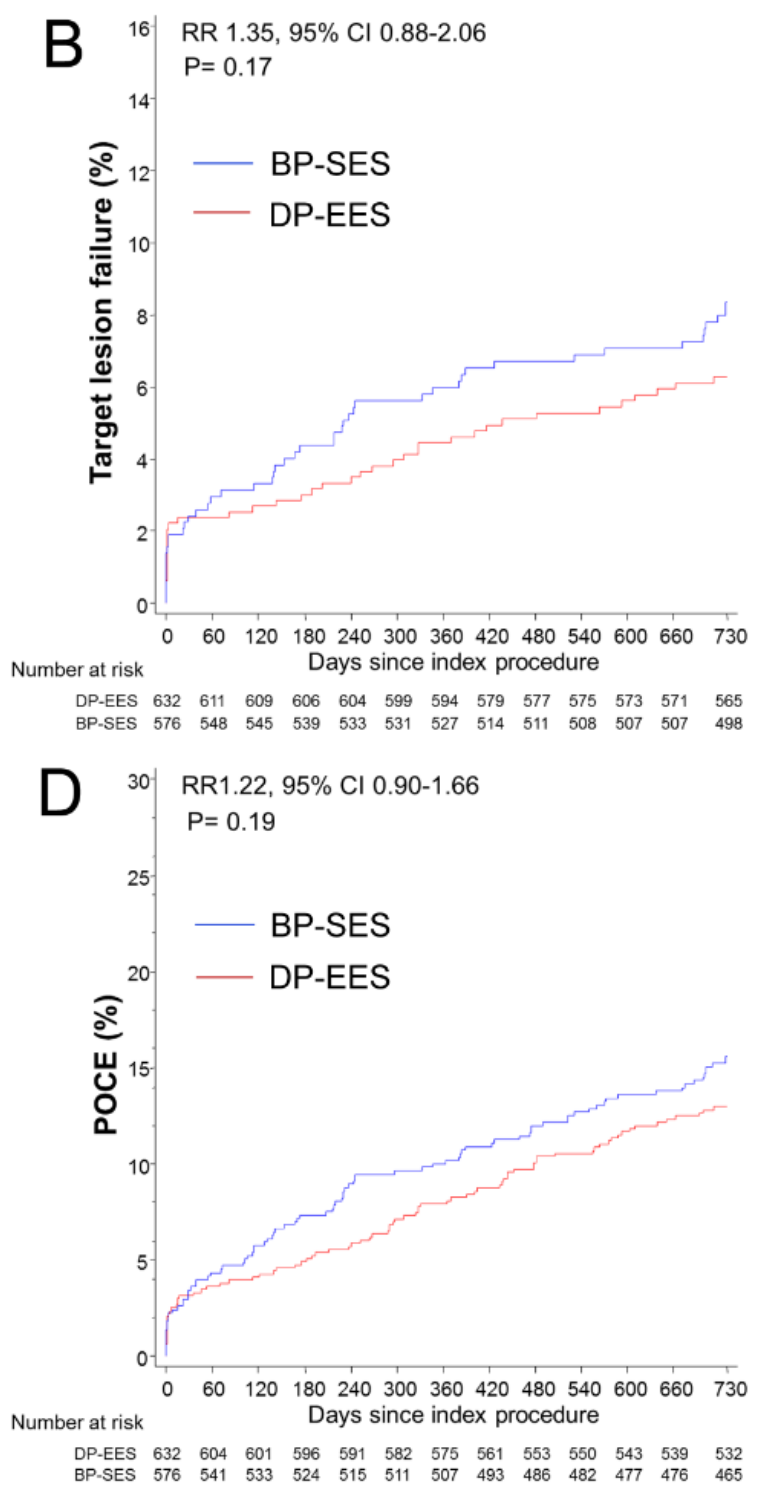




\section{Tables}

\section{Table 1}

Baseline clinical characteristics

\begin{tabular}{lccc}
\hline \multicolumn{1}{c}{ Variable } & $\begin{array}{c}\text { Complex patients } \\
(\mathbf{n = 9 1 1})\end{array}$ & $\begin{array}{c}\text { Simple patients } \\
\mathbf{( n = 1 , 2 0 8 )}\end{array}$ & P value \\
\hline Age (years) & $67.3 \pm 12.3$ & $65.1 \pm 10.7$ & $<0.001$ \\
Men & $678(74.4 \%)$ & $956(79.1 \%)$ & 0.01 \\
Body mass index $\left(\mathrm{kg} / \mathrm{m}^{2}\right)$ & $27.8 \pm 4.6$ & $27.5 \pm 4.4$ & 0.18 \\
Diabetes mellitus & $300(32.9 \%)$ & $186(15.4 \%)$ & $<0.001$ \\
$\quad$ Insulin-treated & $160(17.6 \%)$ & 0 & $<0.001$ \\
Hypertension & $628 / 909(69.1 \%)$ & $806(66.7 \%)$ & 0.26 \\
Hypercholesterolemia & $603(66.2 \%)$ & $825(68.4 \%)$ & 0.30 \\
Current smoker & $244 / 910(26.8 \%)$ & $365(30.3 \%)$ & 0.09 \\
Family history of CAD & $241 / 907(26.6 \%)$ & $346(28.7 \%)$ & 0.28 \\
Previous PCI & $308(33.8 \%)$ & $309(25.6 \%)$ & $<0.001$ \\
Previous coronary bypass & $125(13.7 \%)$ & $86(7.1 \%)$ & $<0.001$ \\
Atrial fibrillation & $77(8.5 \%)$ & $86(7.1 \%)$ & 0.28 \\
Peripheral vascular disease & $95(10.4 \%)$ & $81(6.7 \%)$ & 0.00 \\
Renal dysfunction (GFR $<60$ ml/min) & $281(32.7 \%)$ & 0 & $<0.001$ \\
Clinical presentation & & & $<0.001$ \\
$\quad$ Unstable angina pectoris & $48(5.3 \%)$ & $104(8.6 \%)$ & $<0.001$ \\
$\quad$ NSTEMI & $172(18.9 \%)$ & $400(33.1 \%)$ & \\
$\quad$ STEMI & $339(37.2 \%)$ & $68(5.6 \%)$ & 0 \\
$\quad$ Acute STEMI within $24 \mathrm{~h}$ & $318(34.9 \%)$ & $635(52.6 \%)$ & 0 \\
$\quad$ Stable angina / silent ischemia & $352(38.6 \%)$ & & \\
Left ventricular ejection fraction $\leq 30 \%$ & $82(11.2 \%)$ & & \\
\hline
\end{tabular}

BP-SES = biodegradable polymer sirolimus-eluting stent; CAD = coronary artery disease; DP-EES = durable polymer everolimus-eluting stent; PCI = percutaneous coronary intervention. 


\section{Table 2}

Baseline lesion and procedural characteristics

\begin{tabular}{|c|c|c|c|}
\hline Variable & $\begin{array}{l}\text { Complex patients } \\
\qquad(\mathrm{n}=911)\end{array}$ & $\begin{array}{l}\text { Simple patients } \\
\qquad(\mathrm{n}=\mathbf{1 , 2 0 8 )}\end{array}$ & P value \\
\hline $\begin{array}{l}\text { Number of lesions } \\
\text { Target-vessel location per lesion }\end{array}$ & 1,422 & 1,717 & \\
\hline Left main artery & 46 (3.2\%) & $10(0.6 \%)$ & $<0.001$ \\
\hline $\begin{array}{l}\text { Left anterior descending artery } \\
\text { Left circumflex artery }\end{array}$ & $\begin{array}{l}529(37.2 \%) \\
301(21.2 \%)\end{array}$ & $\begin{array}{l}799(46.5 \%) \\
410(23.9 \%)\end{array}$ & $\begin{array}{c}<0.001 \\
0.06\end{array}$ \\
\hline Right coronary artery & 459 (32.3\%) & 498 (29\%) & 0.03 \\
\hline Bypass graft & 87 (6.4\%) & 0 & \\
\hline Number of treated lesions per patient & & & 0.009 \\
\hline 1 & $560(61.5 \%)$ & $811(67.1 \%)$ & \\
\hline 2 & $233(25.6 \%)$ & $300(24.8 \%)$ & \\
\hline 3 & 87 (9.5\%) & $83(6.9 \%)$ & \\
\hline 4 or more & $31(3.4 \%)$ & $14(1.2 \%)$ & \\
\hline Type of intervention per lesion* & & & 0.49 \\
\hline Stenting & $1,355(95.3 \%)$ & $1,645(95.8 \%)$ & \\
\hline Ballooning & $62(4.4 \%)$ & 67 (3.9\%) & \\
\hline Bypass grafting & $1(0.1 \%)$ & $2(0.1 \%)$ & \\
\hline Failed PCI & $4(0.3 \%)$ & $3(0.2 \%)$ & \\
\hline Restenotic lesion & $180 / 1,421(12.7 \%)$ & $0(0.0 \%)$ & \\
\hline Total occlusion & $330 / 1,418(23.3 \%)$ & $201(11.7 \%)$ & $<0.001$ \\
\hline Thrombus aspiration & $199 / 1,420(14.0 \%)$ & 72 (4.2\%) & $<0.001$ \\
\hline Number of stents & $1.33 \pm 0.66$ & $1.32 \pm 0.60$ & 0.79 \\
\hline Total stent length (mm) & $27.46 \pm 17.76$ & $26.03 \pm 14.59$ & 0.014 \\
\hline Maximum stent diameter per lesion (mm) & $3.07 \pm 0.50$ & $3.01 \pm 0.48$ & 0.001 \\
\hline Overlapping stents & $299(22.1 \%)$ & 367 (22.3\%) & 0.93 \\
\hline Long lesion (>20 mm) & $56(55.8 \%)$ & $909(55.3 \%)$ & 0.74 \\
\hline Small-vessel per lesion $(<2.75 \mathrm{~mm})$ & $555(41 \%)$ & $737(44.8 \%)$ & 0.03 \\
\hline Bifurcation treatment & $222(15.7 \%)$ & $300(17.6 \%)$ & 0.16 \\
\hline Type of stent per lesion & & & 0.047 \\
\hline BP-SES & $739(54.5 \%)$ & $771(46.9 \%)$ & \\
\hline DP-EES & $616(45.5 \%)$ & $871(52.9 \%)$ & \\
\hline Other drug-eluting stent & 0 & $2(0.1 \%)$ & \\
\hline Bare-metal stent & 0 & $5(0.3 \%)$ & \\
\hline
\end{tabular}

*P-value for stenting vs. non-stenting per patient.

Abbreviations as in Table 1. 


\section{Table 3}

Clinical outcomes at 2 years

\begin{tabular}{|c|c|c|c|c|}
\hline Variable & $\begin{array}{c}\text { Complex patients } \\
(\mathrm{n}=911)\end{array}$ & $\begin{array}{l}\text { Simple patients } \\
\qquad(\mathrm{n}=1208)\end{array}$ & $\begin{array}{c}\text { Risk Ratio } \\
(95 \% \mathrm{CI})\end{array}$ & P value \\
\hline All-cause death & $70(7.8 \%)$ & $34(2.9 \%)$ & $2.81(1.87-4.24)$ & $<0.001$ \\
\hline Cardiac death & $47(5.3 \%)$ & $19(1.6 \%)$ & $3.38(1.98-5.76)$ & $<0.001$ \\
\hline Myocardial infarction (any) & $71(8.3 \%)$ & $64(5.4 \%)$ & $1.51(1.08-2.11)$ & 0.016 \\
\hline Target-vessel myocardial infarction & $52(6.0 \%)$ & $36(3 \%)$ & $1.96(1.28-2.99)$ & 0.002 \\
\hline Repeat revascularization (any) & $126(14.8 \%)$ & $113(9.8 \%)$ & $1.55(1.21-2.00)$ & 0.001 \\
\hline Clinically-indicated TLR & $66(7.8 \%)$ & $44(3.9 \%)$ & $2.08(1.42-3.04)$ & $<0.001$ \\
\hline Clinically-indicated TVR & $85(10.0 \%)$ & $60(5.3 \%)$ & $1.97(1.42-2.74)$ & $<0.001$ \\
\hline Target lesion failure* & $128(14.5 \%)$ & $86(7.4 \%)$ & $2.05(1.56-2.69)$ & $<0.001$ \\
\hline Target vessel failure ${ }^{* *}$ & $146(16.6 \%)$ & $105(9 \%)$ & $1.92(1.49-2.47)$ & $<0.001$ \\
\hline Patient-oriented composite endpoint ${ }^{* * *}$ & $204(23 \%)$ & $169(14.4 \%)$ & $1.67(1.36-2.05)$ & $<0.001$ \\
\hline BARC $\geq 3$ bleeding & $41(4.7 \%)$ & $31(2.6 \%)$ & $1.81(1.13-2.88)$ & 0.01 \\
\hline \multicolumn{5}{|l|}{ Stent thrombosis } \\
\hline Definite & $14(1.6 \%)$ & $5(0.4 \%)$ & $3.82(1.37-10.63)$ & 0.006 \\
\hline Probable & 43 (4.9\%) & 31 (2.6\%) & $1.87(1.18-2.97)$ & 0.007 \\
\hline Definite or probable & $56(6.4 \%)$ & 34 (2.9\%) & $2.23(1.46-3.42)$ & $<0.001$ \\
\hline
\end{tabular}

BARC = Bleeding Academic Research Consortium; TLR = target-lesion revascularization; TVR = target-vessel revascularization.

* Composite of cardiac death, target-vessel MI, and clinically indicated TLR.

** Composite of cardiac death, any MI, and TVR.

*** Composite of death, MI, or any repeat revascularization. 
Published in final edited form as: Am J Cardiol. 2017 Feb 15;119(4):501-507.

doi: 10.1016/j.amjcard.2016.10.038

-20 -

\section{Table 4}

Clinical outcomes at 2 years in complex and simple patients stratified by allocated stent type

\begin{tabular}{|c|c|c|c|c|c|c|c|c|}
\hline & \multicolumn{4}{|c|}{ Complex patients } & \multicolumn{4}{|c|}{ Simple patients } \\
\hline Cardiac death & $18(3.9 \%)$ & $29(7 \%)$ & $0.54(0.30-0.97)$ & 0.036 & $15(2.7 \%)$ & $4(0.7 \%)$ & $4.22(1.40-12.73)$ & 0.005 \\
\hline Myocardial infarction (any) & $35(7.6 \%)$ & $36(9.1 \%)$ & $0.84(0.53-1.34)$ & 0.46 & $27(4.8 \%)$ & 37 (5.9\%) & $0.81(0.49-1.33)$ & 0.41 \\
\hline Cardiac death or MI & $50(10.7 \%)$ & $61(14.8 \%)$ & $0.71(0.49-1.03)$ & 0.07 & $42(7.5 \%)$ & $40(6.4 \%)$ & $1.17(0.76-1.80)$ & 0.48 \\
\hline Repeat revascularization (any) & $69(15.1 \%)$ & $57(14.5 \%)$ & $1.06(0.75-1.51)$ & 0.74 & 57 (10.5\%) & $56(9.1 \%)$ & $1.16(0.80-1.68)$ & 0.43 \\
\hline Clinically-indicated TLR & 37 (8.1\%) & $29(7.5 \%)$ & $1.12(0.69-1.82)$ & 0.65 & $22(4.2 \%)$ & $22(3.6 \%)$ & $1.13(0.62-2.04)$ & 0.69 \\
\hline Clinically-indicated TVR & 48 (10.5\%) & 37 (9.5\%) & $1.14(0.74-1.75)$ & 0.55 & $29(5.5 \%)$ & $31(5.1 \%)$ & $1.06(0.64-1.75)$ & 0.83 \\
\hline \multicolumn{9}{|l|}{ Stent thrombosis } \\
\hline Definite & $9(1.9 \%)$ & $5(1.2 \%)$ & $1.57(0.52-4.68)$ & 0.42 & $2(0.4 \%)$ & $3(0.5 \%)$ & $0.75(0.12-4.52)$ & 0.75 \\
\hline Probable & $18(3.9 \%)$ & $25(6.1 \%)$ & $0.62(0.34-1.14)$ & 0.12 & $12(2.1 \%)$ & 19 (3\%) & $0.70(0.34-1.44)$ & 0.32 \\
\hline Definite or probable & $26(5.6 \%)$ & $30(7.3 \%)$ & $0.75(0.44-1.27)$ & 0.28 & $14(2.5 \%)$ & $20(3.2 \%)$ & $0.77(0.39-1.54)$ & 0.46 \\
\hline BARC $\geq 3$ bleeding & $21(4.4 \%)$ & 20 (4.9\%) & $0.91(0.49-1.68)$ & 0.76 & $15(2.7 \%)$ & $16(2.6 \%)$ & $1.04(0.52-2.11)$ & 0.90 \\
\hline
\end{tabular}

Abbreviations as in Table 3. 